\title{
The Effects of Entrepreneurial Context on Entrepreneurial Cognition
}

\author{
Lu Cheng ${ }^{1, a, *}$, Zewei Yu' ${ }^{1, b}$ and Rui Wang',c \\ ${ }^{1}$ Faculty of Management \& Economics, Dalian University of Technology, Linggong Road, Dalian, \\ China \\ a136034878@qq.com, ${ }^{b}$ zeweiyu@foxmail.com, ${ }^{c} 1773594298 @ q q . c o m$
}

Keywords: Entrepreneurial context, entrepreneurial cognition

\begin{abstract}
In this paper, through the empirical study on the start-ups in Dalian Economic and Technological Development Zone, we examine how entrepreneurial context influences entrepreneurial cognition. We identify entrepreneurial context in three dimensions, i.e., the guided, the motivated and the supported context. We find that each kind of entrepreneurial exerts a positive effect on entrepreneurial cognition.
\end{abstract}

\section{Introduction}

Exploring the effects of entrepreneurial context on entrepreneurial cognition plays an important role in instructing the improvement of regional entrepreneurial activity.

Currently, research on entrepreneur and entrepreneurship reaches a consensus that entrepreneurial context contains several sub-contexts ${ }^{[1-2]}$. However, the effects of various sub entrepreneurial context on entrepreneurial cognition, and the differences between these effects, are still uncertain, which are necessary to be solved.

In this paper, we aim to uncover how different sub-contexts influence entrepreneurial cognition through the empirical study on the start-ups in Dalian Economic and Technological Development Zone (DLETDZ). First, after a brief review on the literature of entrepreneurial context and entrepreneurial cognition, we identify entrepreneurial context into three dimensions, i.e. the guided, the motivated and the supported context, and propose the hypothesis about the relationships between entrepreneurial context and entrepreneurial cognition. Second, based on the collected data from DLETZD, we examine the hypothesis by factor analysis, correlation analysis and hierarchical regression in SPSS 22.0. At last, we discuss the results and come to the conclusion.

\section{Theory and hypothesis}

\subsection{Entrepreneurial context}

Different scholars take different views on the identification of entrepreneurial context. For instance, Ucbasaran (2001) identified the entrepreneurial environment from two perspectives: resource and evolution, and considered that the environment is a pool of resources with organizations entering into transactional relationships with environmental factors ${ }^{[3]}$. Welter (2011) 
pointed out that the context is more applicable to the research topic of entrepreneurial activities compared to the environment ${ }^{[2]}$. Autio (2014) considered that entrepreneurial context is situational opportunities and constraints that affect the occurrence and meaning of organizational behavior as well as functional relationships between variables ${ }^{[4]}$. It is the context that regulates what individuals and teams get to see, what choices they are likely to make, and what the outcomes of those choices are likely to be.

Since entrepreneurial context can be identified from the utility characteristics, we identify it into the dimensions of "guided", "motivated" and "supported". The guided context refers to the collection of contextual elements that guide entrepreneurial activities. The motivated context refers to the collection of contextual elements that stimulate entrepreneurial activities. The supported context refers to the collection of contextual elements that support entrepreneurial activities.

\subsection{Entrepreneurial cognition}

The distinction between entrepreneur and non-entrepreneur is in entrepreneurial thinking and cognition. Ucbasaran et al., (2001) considered that entrepreneurial cognition is the way entrepreneurs think and make decisions in the face of uncertainty ${ }^{[3]}$. Mitchell et al.,(2002) pointed out that entrepreneurial cognition is the knowledge structure for entrepreneurs to evaluate, judge and make decisions on key business issues such as business opportunities, financing and growth ${ }^{[5]}$. Chaston and Smith (2012) argued that entrepreneurial cognition is the information process for entrepreneurs to solve problems and make decisions ${ }^{[6]}$. Generally, entrepreneurial cognition mainly focuses on the mental model of the entrepreneurs' opportunity identification and business development. With a unique entrepreneurial cognition, good entrepreneurs can even identify entrepreneurial opportunities in the markets with high uncertainty.

Further, entrepreneurial cognition can be identified from the dimensions of structure and process. For instance, Busenitz and Lau (1996) divided entrepreneurial cognition into the aspects of cognitive structure and cognitive process ${ }^{[7]}$. Mitchell (2000) categorized entrepreneurial cognition as "venture arrangements script", "venture willingness script" and "venture ability script", all of which has been widely recognized ${ }^{[8]}$. Venture arrangements script refers to the knowledge structure related to various types of resources, relationships, and capabilities those are required in the preparatory process of entrepreneurship. Venture willingness script refers to the knowledge structure related to risk-reward in the entrepreneurial decision-making process. Venture ability script refers to the knowledge structure related to the essential knowledge and skills in the process of entrepreneurship implementation. In this paper, we identify and evaluate entrepreneurial cognition as Mitchell (2000) did.

\subsection{The entrepreneurial context and entrepreneurial cognition}

\subsubsection{The guided context and entrepreneurial cognition}

The guided context mainly refers to the collection of cultural elements that play a guiding role in entrepreneurial activities. In strong entrepreneurial-guided culture, managers generally recognize that the entrepreneurial process and efforts can achieve the expectations of the future, including entrepreneurial resource support, tax preference and higher social status of entrepreneurs. It can attract those who are eager to exchange for high return and social status with low opportunity cost to join the business. In high power distance culture, the phenomenon that stratum is solidified and obeys authority is widespread which greatly reduces the mobility of social strata ${ }^{[9]}$. On one hand, lower-level social members lack the necessary resources and capabilities for entrepreneurship, and the sensitivity to the entrepreneurial opportunities. On the other hand, the wealth that 
entrepreneurship creates will break the existing social strata and economic structure, and will be obstructed by the high power ${ }^{[10]}$. Thus, some scholars have pointed out that situations with strong entrepreneurial orientation often have contexts with low power distance characteristics ${ }^{[11]}$. Thus, we propose hypothesis 1 :

H1: The guided context will positively influence entrepreneurial cognition.

\subsubsection{The motivational context and entrepreneurial cognition}

The motivated context mainly refers to the collection of institution elements that stimulate entrepreneurial activities. The motivated context inducts individual behavior by the means of rule-setting, monitoring and sanctioning activities. The regulative emphasis is on conformity to rules ${ }^{[12]}$. The motivated context expresses support and guidance to the entrepreneurship by policies and regulations. On one hand, the strong motivational context can reduce the entrepreneurs' uncertainty that caused by the lack of information, knowledge and resources, and strengthen accepter level of the uncertainty by intellectual property protection ${ }^{[13]}$. It can reduce the adverse effect of entrepreneurial cognition that caused by uncertainty expectation. On the other hand, the strong motivational context can increase their survival prospects for new ventures ${ }^{[14]}$. It decrease operating costing and improves the possibility for the support of social resources. Thus we propose hypothesis2:

H2: The motivated context will positively influence entrepreneurial cognition.

\subsubsection{The supported context and entrepreneurial cognition}

The supported context mainly refers to refers to the collection of business and society elements that directly affect entrepreneurial activities. Entrepreneurial opportunities and the environment with rich entrepreneurial resources are the basic consideration of entrepreneurship decision. On one hand, the uncertainty of the business environment is the foundation of enterprise survival and development. The market, technology, competition and the critical resource for the uncertainty provide innovative development opportunities for business enterprises ${ }^{[15]}$. On the other hand, entrepreneurs' social capital provides an important channel for their firms' accessing external key resources. The resources that get from social network are more competitive and stronger in quality, relevance and timeliness ${ }^{[16]}$. Supportive business environment and social network can make the firms more perceive and capture potential business opportunities. Thus we propose hypothesis3:

H3: The supported context will positively influence entrepreneurial cognition.

\section{Methodology}

\subsection{Data collection}

To test the above hypotheses, we refer to the existing Action Research Arm Test and combine the theme of entrepreneurial context to design the variable scale for this study. In the formal investigation, we select technological entrepreneurial enterprises in DLETDZ.

The entrepreneurs were investigated by the questionnaire survey. In order to avoid the semantic bias between the description of the item and connotation, before the formal investigation, the preliminary research was conducted in start-up workshop which is the state-level technology entrepreneurship incubator. Based on the feedback, the questionnaire was revised. The items are measured by Likert-5 scoring, except for the background information of entrepreneurs and start-ups. The questionnaires were mainly sent through face-to-face interviews, paying one's a visit and email. A total of 228 questionnaires are returned, and 160 are valid. The effective rate is $70.18 \%$. The overall characteristics of the survey sample are shown in Table1. 
Table1 The overall characteristics of the survey sample

\begin{tabular}{|c|c|c|c|}
\hline Sample-feature & Type & Figure & Percentage(\%) \\
\hline \multirow{4}{*}{ Gender } & Male & 86 & 53.75 \\
\hline \multirow{4}{*}{ Age } & Female & 74 & 46.25 \\
\hline & Younger than 30 & 34 & 21.25 \\
\cline { 2 - 4 } & $31-40$ years old & 111 & 69.38 \\
\cline { 2 - 4 } & 41-50 years old & 14 & 8.75 \\
\cline { 2 - 4 } & Older than 50 & 1 & 0.62 \\
\hline \multirow{4}{*}{ Education } & Bachelor or below & 102 & 63.75 \\
\cline { 2 - 4 } & Master & 52 & 32.5 \\
\cline { 2 - 4 } & Doctor or above & 6 & 3.75 \\
\hline \multirow{5}{*}{ Overseas experience } & No & 55 & 34.37 \\
\cline { 2 - 4 } & Less than 3 years & 61 & 38.13 \\
\cline { 2 - 4 } & 4-6 years & 30 & 8.75 \\
\cline { 2 - 4 } & More than 7 years & 14 & 50 \\
\hline \multirow{3}{*}{ working experience } & Less than 5 years & 80 & 45 \\
\cline { 2 - 4 } & 6-15 years & 72 & 5 \\
\cline { 2 - 4 } & More than 16 years & 8 & \\
\hline
\end{tabular}

\subsection{Measurement}

\subsubsection{Entrepreneurial cognition}

We identify and evaluate entrepreneurial cognition as Mitchell (2000) did ${ }^{[8]}$. In detail venture arrangements script is measured by the awareness of necessary preparations for starting entrepreneurial activities; venture willingness script is measured by the awareness of the willingness to create a new company; venture ability script is measured by the awareness of the competence

\subsubsection{Entrepreneurial context}

We use Girlando and Eduljee (2010)'s scale to identify and evaluate the guided context, which includes four items, i.e., maintaining good relationships with leaders, seeking opinions from subordinates, posting different opinions less than leaders and avoiding dual leadership ${ }^{[17]}$. We use Busenitz (2000)'s scale to identify and evaluate the motivated context, which includes five items i.e., supporting entrepreneurship, government procurement, special policies, subsidizing entrepreneurship service and encouraging secondary entrepreneurship ${ }^{[18]}$. We access the supported context from the perspective of social network and business environment. The former indicator is measured by Peng and Luo (2000)'s scale ${ }^{[19]}$, and the latter is measured by Watson (2007)'s scale [20].

\subsubsection{Control variable}

Taking into account the possible impact of entrepreneurs' personalities, we take the factors of entrepreneur education experience and working experience as control variables.

\section{Analysis}

The four Croncach $\alpha$ of the guided, the motivated, the supported context, and entrepreneurial context are $0.808,0.785$ and 0.792 , respectively, which show the measurement is good in validity. 
In addition, the factor loading is greater than 0.6 indicating the measurement is good in reliability.

\subsection{Correlation analysis}

The correlation analysis result is shown in Table 2. The correlation coefficients between the three contexts and entrepreneurial cognition are 0.343(p<0.01), 0.001 $(\mathrm{p}<0.05)$ and $0.218(\mathrm{p}<0.01)$, respectively.

Table2 Average, Standard deviation and Correlation coefficient

\begin{tabular}{|l|c|c|c|c|c|c|c|c|}
\hline \multicolumn{1}{|c|}{ Variable } & $\mathrm{M}$ & $\mathrm{SD}$ & $\mathrm{A}$ & $\mathrm{b}$ & $\mathrm{c}$ & $\mathrm{d}$ & $\mathrm{e}$ & $\mathrm{f}$ \\
\hline a. Working years & 2.588 & 0.850 & 1 & & & & & \\
\hline b. Education & 1.400 & 0.563 & $0.308^{* *}$ & 1 & & & & \\
\hline $\begin{array}{l}\text { c. The guided context } \\
\begin{array}{l}\text { d. The motivated } \\
\text { context }\end{array}\end{array}$ & 3.112 & 0.464 & $-0.313^{* *}$ & $-0.188^{*}$ & 1 & & & \\
\hline $\begin{array}{l}\text { e. The supported context } \\
\text { f. Entrepreneurial } \\
\text { cognition }\end{array}$ & 1.670 & 0.370 & -0.056 & 0.001 & -0.052 & 1 & & \\
\hline
\end{tabular}

$* * \mathrm{p}<0.01, * \mathrm{p}<0.05$

\subsection{Hierarchy regression analysis}

Table 3 is the hierarchy regression analysis results summary of the entrepreneurial context that contains main effect and moderating effect with entrepreneurial cognition. Model 1 is the regression model of the control variables with the dependent variables. Model 2 is the main effect regression model of the control variables and independent variables with the dependent variables. Model 3, Model 4 and Model 5 are the moderating effect regression models those are added moderating effect interaction step by step.

Table3 Hierarchical regression analysis results of entrepreneurial cognition of entrepreneurial context

\begin{tabular}{|c|c|c|c|c|c|}
\hline & \multicolumn{5}{|c|}{ Entrepreneurial cognition } \\
\cline { 2 - 6 } & Model 1 & Model 2 & Model 3 & Model 4 & Model 5 \\
\hline Working experience & -0.001 & $0.221^{*}$ & $0.263^{* *}$ & $0.221^{*}$ & $0.237^{* *}$ \\
\hline Education & 0.007 & -0.082 & -0.124 & -0.091 & -0.108 \\
\hline Guided context & & $0.361^{* *}$ & $2.833^{*}$ & 1.382 & $0.385^{* *}$ \\
\hline Motivated context & & $0.178^{*}$ & $2.134^{*}$ & 0.885 & 0.121 \\
\hline Supported context & & $0.321^{* *}$ & $1.552^{* *}$ & 0.709 & 1.110 \\
\hline Motivated context $\times$ guided context & & & $3.092^{*}$ & & \\
\hline Supported context $\times$ guided context & & & $1.127^{*}$ & & \\
\hline Guided context $\times$ Motivated context & & & & -1.218 & \\
\hline Supported context $\times$ Motivated context & & & & 0.386 & \\
\hline Guided context $\times$ Supported context & & & & & 0.115 \\
\hline Motivated context $\times$ Friendly context & & & & & 0.702 \\
\hline R2 after adjusting & 0.013 & 0.168 & 0.181 & 0.169 & 0.163 \\
\hline $\mathrm{F}$ & 0.004 & $5.400^{* *}$ & $6.020^{* *}$ & $5.629^{* *}$ & $5.427 * *$ \\
\hline
\end{tabular}

$* * \mathrm{p}<0.01, * \mathrm{p}<0.05$ 
Model 2 shows that the guided, the motivated and the supported context respectively has a positive effect on entrepreneurial cognition, significantly $(\beta=0.361, p<0.01 ; \beta=0.178, p<0.05$; $\beta=0.321, \mathrm{p}<0.01$ ). Thus, $\mathrm{H} 1, \mathrm{H} 2$ and $\mathrm{H} 3$ respectively pass the test.

Additionally, Model 3 shows that the guided context positively moderates the influences of the other two contexts on entrepreneurial cognition, $(\beta=0.178, \mathrm{p}<0.05 ; \beta=0.321, \mathrm{p}<0.01)$. That is to say the guided context has a positive effect on the interaction between the motivated and the supported context.

Moreover, Model 4 and Model 5 respectively reveal that the moderating effects of motivational context and that of support context are not significant $(\beta=-1.218, p>0.1, \beta=0.386, p>0.1 ; \beta=0.115$, $\mathrm{p}>0.1 ; \beta=0.163, \mathrm{p}>0.1)$. Therefore the motivated context does not impact on the interaction between the guided and the supported context, and the support context does not impact on the interaction between the guided and the motivated context either.

\section{Discussion and conclusion}

Our analysis shows that there is no strict boundary between the three scripts of entrepreneurial cognition, but tends to behave as a cognitive system of interactive infiltration. First, the oriented context has a positive effect on entrepreneurial cognition. The stronger the guided context, the lower power distance in social cultural value is. When the power distance is high, the unequal distribution of power and status in society is aggravated. Individuals in high social class will seize resource, block information flow and resist reciprocal behavior across social strata, in order to solidify their current status. When the power distance of the entire society is low, resource and information will flow between different social strata. The reciprocal behavior occurs frequently across social strata. This shows that in a strong oriented context, the entire society has high expectations of resource flow, information sharing and reciprocity, which will enhance the cognitive structure of entrepreneurs for entrepreneurial preparation. At the same time, the distance that can be straddled between social strata allows lower social class to have more autonomy and tend to engage in risky actions to promote social strata, which will enhance the cognitive structure of entrepreneurs for entrepreneurial willingness.

Second, the motivated context has a positive effect on entrepreneurial cognition. The stronger motivated context indicates that the government is much more committed to improving the survival and development space of start-ups, promoting the free resources to start-ups and reducing the cost of acquiring resources for start-ups. At the same time, the encouragement and guidance of good legal policies can eliminate the competitive disadvantages caused by the lack of legitimacy of start-ups. Information processing theory believes that the legal system will directly affect the entrepreneurial entrepreneurs' knowledge structure of "entrepreneurial entry", such as reserve of entrepreneurial resource and the formation of entrepreneurial willingness. In addition to the support and encouragement of entrepreneurial activity in institutional policies, the strong motivational context will also improve and develop entrepreneurial service organizations, enhance entrepreneurs' expectations for the promotion of entrepreneurial resources, technology and management capabilities. Meanwhile, it can strengthen entrepreneurs' cognitive structure of entrepreneurial ability

Third, the supported context has a positive effect on entrepreneurial cognition. The stronger supported context indicates that the uncertain business situation provides more opportunities and the social circle gives entrepreneurs more substantial direct resources. Entrepreneurship is a dynamic adaptation process in which entrepreneurs constantly search for business opportunities and gather resources. On one hand, most entrepreneurs prefer to find opportunities from uncertainty, showing the risk preference for uncertainty. On the other hand, entrepreneurs often look for emotional 
support, reliable information, lower cost entrepreneurial resources and the help of solving problems in close social circles. The uncertainty of the business situation and the support of friends and family will enhance entrepreneurs' cognitive structure of entrepreneurial willingness. At the same time, compared to institutional context, Chinese entrepreneurs are more inclined to rely on tight social circle for scarce resource, policy protection and legitimacy. The richness of entrepreneurs and entrepreneurial team can enhance entrepreneurs' knowledge structure of entrepreneurial preparation. Furthermore, the widespread popularity of proven business model within the industry and the successful entrepreneurial models within the entrepreneur's social circle can enhance entrepreneurs' knowledge structure of entrepreneurial capabilities.

\section{References}

[1] Johns G. The essential impact of context on organizational behavior [J]. Academy of Management Review, 2006, 31(2): 386-408.

[2] Welter F. Contextualizing entrepreneurship-conceptual challenges and ways forward [J]. Entrepreneurship Theory and Practice, 2011, 35(1): 165-184.

[3] Ucbasaran D, Westhead P, Wright M. The focus of entrepreneurial research: Contextual and process issues [J]. Entrepreneurship Theory and Practice, 2001, 25(4): 57-80.

[4] Autio E, Kenney M, Mustar P, et al. Entrepreneurial innovation: The importance of context [J]. Research Policy, 2014, 43(7): 1097-1108.

[5] Mitchell R K, Busenitz L, Lant T, et al. Toward a theory of entrepreneurial cognition: Rethinking the people side of entrepreneurship research [J]. Entrepreneurship Theory and Practice, 2002, 27(2): 93-104.

[6] Chaston I, Sadler-Smith E. Entrepreneurial cognition, entrepreneurial orientation and firm capability in the creative industries [J]. British Journal of Management, 2012, 23(3): 415-432.

[7] Busenitz L W, Lau C M. Growth intentions of entrepreneurs in a transitional economy: The People's Republic of China [J]. Entrepreneurship Theory and Practice, 2001, 26(1): 5-21.

[8] Mitchell $R K$, Smith B, Seawright $K W$, et al. Cross-cultural cognitions and the venture creation decision[J]. Academy of Management Journal, 2000, 43(5): 974-993.

[9] Daniels M A, Greguras G J. Exploring the nature of power distance: Implications for micro-and macro-level theories, processes, and outcomes [J]. Journal of Management, 2014, 40(5): 1202-1229.

[10] Sambharya R, Musteen M. Institutional environment and entrepreneurship: An empirical study across countries [J]. Journal of International Entrepreneurship, 2014, 12(4): 314-330.

[11] Lee S M, Peterson S J. Culture, entrepreneurial orientation, and global competitiveness [J]. Journal of World Business, 2000, 35(4): 401-416.

[12] Veciana J M, Urbano D. The institutional approach to entrepreneurship research. Introduction [J]. 2008.

[13] Bowen H P, De Clercq D. Institutional context and the allocation of entrepreneurial effort [J]. Journal of International Business Studies, 2008, 39(4): 747-767.

[14] Bruton G D, Ahlstrom D, Li H L. Institutional theory and entrepreneurship: where are we now and where do we need to move in the future?[J]. Entrepreneurship Theory and Practice, 2010, 34(3): 421-440.

[15] Yusuf A. Environmental uncertainty, the entrepreneurial orientation of business ventures and performance[J]. International Journal of Commerce and Management, 2002, 12(3/4): 83-103.

[16] Uzkurt C, Kumar R, Kimzan H S, et al. The impact of environmental uncertainty dimensions on organisational innovativeness: An empirical study on SMEs [J]. International Journal of Innovation Management, 2012, 16(02): 1250015.

[17] Girlando A P, Eduljee N B. An empirical investigation of the malleability of Hofstede's cultural dimensions: The case of the United States and Russia [J]. Journal of Transnational Management, 2010, 15(3): 265-289.

[18] Busenitz L W, Gomez C, Spencer J W. Country institutional profiles: Unlocking entrepreneurial phenomena [J]. Academy of Management Journal, 2000, 43(5): 994-1003.

[19] Peng MW, Luo Y. Managerial ties and firm performance in a transition economy: The nature of a micro-macro link [J]. Academy of Management Journal, 2000, 43(3): 486-501.

[20] Watson J. Modeling the relationship between networking and firm performance [J]. Journal of Business Venturing, 2007, 22(6): 852-874. 